Utah State University

DigitalCommons@USU

\title{
Quantifying the Transient Response of Ecological-Economic Systems to Perturbations
}

Amitrajeet A. Batabyal

Utah State University

Follow this and additional works at: https://digitalcommons.usu.edu/eri

\section{Recommended Citation}

Batabyal, Amitrajeet A., "Quantifying the Transient Response of Ecological-Economic Systems to Perturbations" (1999). Economic Research Institute Study Papers. Paper 174.

https://digitalcommons.usu.edu/eri/174

This Article is brought to you for free and open access by the Economics and Finance at DigitalCommons@USU. It has been accepted for inclusion in Economic Research Institute Study Papers by an authorized administrator of DigitalCommons@USU. For more information, please contact digitalcommons@usu.edu.

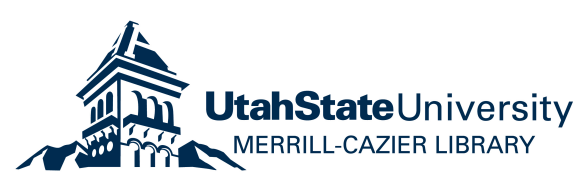


Economic Research Institute Study Paper

ERI \#99-24

\title{
QUANTIFYING THE TRANSIENT RESPONSE OF ECOLOGICAL-ECONOMIC SYSTEMS TO PERTURBATIONS
}

\author{
by \\ AMITRAJEET A. BATABYAL
}

Department of Economics

Utah State University

3530 Old Main Hill

Logan, UT 84322-3530

December 1999 


\title{
QUANTIFYING THE TRANSIENT RESPONSE OF ECOLOGICAL-ECONOMIC SYSTEMS TO PERTURBATIONS
}

\author{
Amitrajeet A. Batabyal, Assistant Professor \\ Department of Economics \\ Utah State University \\ 3530 Old Main Hill \\ Logan, UT 84322-3530
}

The analyses and views reported in this paper are those of the author(s). They are not necessarily endorsed by the Department of Economics or by Utah State University.

Utah State University is committed to the policy that all persons shall have equal access to its programs and employment without regard to race, color, creed, religion, national origin, sex, age, marital status, disability, public assistance status, veteran status, or sexual orientation.

Information on other titles in this series may be obtained from: Department of Economics, Utah State University, 3530 Old Main Hill, Logan, Utah 84322-3530.

Copyright $(\subset) 1999$ by Amitrajeet A. Batabyal. All rights reserved. Readers may make verbatim copies of this document for noncommercial purposes by any means, provided that this copyright notice appears on all such copies. 


\title{
QUANTIFYING THE TRANSIENT RESPONSE OF \\ ECOLOGICAL-ECONOMIC SYSTEMS TO \\ PERTURBATIONS \\ Amitrajeet A. Batabyal
}

\begin{abstract}
Ecologists and economists are increasingly in agreement that ecological and economic systems are linked and that these systems should actually be viewed as one system. Perhaps because this recognition has been very recent, neither ecologists nor economists have studied the short term behavior of jointly determined ecological-economic systems that are subject to perturbations stemming from natural events and the continuance of economic activities. Consequently, the purpose of this paper is to construct a metric that can be used to quantify the transient response of ecological-economic systems to perturbations. This metric is a non-asymptotic measure of an ecological-economic system's resilience.

JEL classification: Q30, D80
\end{abstract}

Key words: ecological-economic system, resilience, transient behavior 


\section{QUANTIFYING THE TRANSIENT RESPONSE OF \\ ECOLOGICAL-ECONOMIC SYSTEMS TO \\ PERTURBATIONS ${ }^{1}$}

\section{Introduction}

Generally speaking, natural systems are subject to two kinds of perturbations. The first kind of perturbation stems from the occurrence of natural events such as droughts and hurricanes. The second kind of perturbation arises from the conduct of economic activities such as fishing and grazing. Inter alia, a recognition of the vulnerability of natural systems to these two kinds of perturbations has led ecologists and economists to conclude that ecological and economic systems should actually be viewed as one system.

With this conclusion, a whole host of questions pertaining to the effective management of ecological-economic systems become salient. In particular, it is now important to know how such systems respond to perturbations. In the ecology literature, the response of ecosystems to perturbations has traditionally been measured by the concept of resilience. Resilience is measured by first constructing a matrix which gives the strength of the interactions between the various species at their equilibrium population densities. The maximal eigenvalue of this matrix is then defined to be the resilience of the ecosystem. Put differently, this notion of resilience measures the rapidity with which a stable ecosystem returns to its original state following a perturbation. ${ }^{2}$

${ }^{1}$ I thank Eric Johnson and an anonymous referee for their comments on a previous draft of this paper. I acknowledge financial support from: (i) the Faculty Research Grant program at Utah State University, and (ii) the Utah Agricultural Experiment Station, Utah State University, Logan, UT 84322-4810, by way of project UTA 024. Approved as journal paper \# 6056. The usual disclaimer applies.

${ }^{2}$ At the very outset, it is important to note that two notions of resilience are prevalent in the ecology literature. The notion that we have just mentioned is the one that has been popularized by Pimm $(1984,1991)$. The other notion of resilience refers to "the amount of disturbance that can be sustained [by an ecosystem] before a change in system control or structure occurs." (Holling et al. 1995, p. 50). This latter notion of resilience was first proposed in Holling (1973). 
Although this methodology for computing resilience has been widely used in the ecology literature, it is important to note that resilience, measured in terms of the maximal eigenvalue of the matrix of interaction effects, is an asymptotic property. In other words, this notion of resilience provides information about the rate of decay of perturbations as time approaches infinity. The short term, transient behavior of an ecosystem is completely ignored. However, from a management perspective, the relevant issue concerns the behavior of an ecological-economic system following a perturbation. Some reflection suggests that for most ecological-economic systems, it is transient behavior that is generally of interest. Indeed, as Batabyal (1998a, 1999a) has noted, knowing how a given ecological-economic system responds to perturbations in the long run, i.e., as time approaches infinity, would not be very helpful because most policy makers set policy—and are interested in the effects of policy_over much shorter time horizons. In addition to this, Neubert and Caswell (1997) have persuasively argued that ecosystems cannot be managed effectively without understanding their transient behavior. In particular, these authors have formally demonstrated that "even in stable, resilient [ecosystems], transient behavior can be dramatic, long lasting, and counterintuitive." (Neubert and Caswell, 1997, p. 654).

Given the significance of transient behavior for the effective management of ecologicaleconomic systems, one can ask about our current level of knowledge regarding the measurement of this kind of short term behavior. Unfortunately, as best as we can tell, this level is very low. In particular, the economics literature appears to have completely ignored this issue. This is, as Dasgupta (1996, p. 390) has noted, a rather sorry state of affairs. Even the vast ecology literature on resilience seems to have focused most of its attention on resilience as an asymptotic property. ${ }^{3}$

${ }^{3}$ For a more detailed corroboration of this claim, see Neubert and Caswell (1997) and the papers cited therein. 
Recognizing the limitations of this asymptotic approach, a small group of ecologists—see DeAngelis (1980, 1992) and Cottingham and Carpenter (1994) - have recently used methods that are not based on eigenvalue analysis, to quantify the transient behavior of ecosystems following perturbations. However, a key problem with these methods is that even for perturbations of the same magnitude, depending on the direction of the perturbation, one gets very different numerical values for ecosystem resilience.

To rectify this and other problems of these non-eigenvalue based methods of computing resilience, Neubert and Caswell (1997) have proposed three metrics that can quantify the transient behavior of an ecosystem following a small perturbation. While their paper is a very useful piece of research, the scope of Neubert and Caswell's (1997) work is limited by the fact that their proposed metrics are all deterministic measures of resilience. Consequently, this line of research is unable to address the Ives (1995, p. 217) criticism that in order to apply generally to ecosystems, resilience measures need "to be defined for stochastic systems in which environmental perturbations are continuous and equilibrium [population] densities are never achieved."

This review of the literature yields three conclusions. First, the economics literature has essentially ignored the question of quantifying the transient behavior of ecological-economic systems that are subject to perturbations. ${ }^{4}$ Second, while the ecology literature has analyzed resilience in the sense of Holling (1973) and in the sense of Pimm (1984) at some depth, most of this analysis has

${ }^{4}$ There is one exception to this generalization. Recently, Perrings (1998) has studied the transient behavior of jointly determined ecological-economic systems. The approach adopted in this paper differs from that used in Perrings (1998) in three important ways. First, we explicitly account for the substitutability between species in the performance of ecological functions. Second, our analysis does not depend on the ecological-economic system following a Markov process. Third, we do not equate the transient resilience of the system with the elements of an appropriately defined stochastic matrix of transition probabilities. For a general discussion of dynamic analysis and stability in the context of purely economic systems, the reader should consult Hahn (1982). 
construed resilience as an asymptotic property. Third, the fledgling ecology literature on the measurement of transient ecosystem behavior has focused on deterministic systems. Given this situation, the objective of this paper is to use the theory of associated random variables to construct a metric that can be used to quantify the transient behavior of a stochastic ecological-economic system that is subject to perturbations. ${ }^{5}$ This is done in section 2 . In section 3 , we summarize our findings, and offer some concluding comments.

\section{A Stochastic Characterization of Transient Ecosystem Behavior}

\subsection{Preliminaries}

Consider a stylized ecological-economic system which consists of $n \in \mathbb{N}$ independent species. Formally, this system can be described by the random vector $S=\left(s_{1}, s_{2}, \ldots, s_{n}\right)$, where $s_{i}, 1 \leq i \leq n$, is a random variable which denotes the state of the ith species. Now proposition 9.7.1 in Ross (1996, pp. 446-7) tells us that the $n$ species are associated. Further, as Shaked and Shanthikumar (1994, p. 118) have noted, this means that for all increasing functions $\varphi_{1}$ and $\varphi_{2}$, the relation

$$
E\left[\varphi_{1}(S) \varphi_{2}(S)\right] \geq E\left[\varphi_{1}(S)\right] E\left[\varphi_{2}(S)\right]
$$

holds, where $E[\cdot]$ is the expectation operator. The reader will note that this notion of association simply formalizes the intuitive idea that for most ecological-economic systems, there generally exists some positive dependence between the various species of the system.

Now as a result of the occurrence of natural events such as droughts and floods, and the continuance of economic activities such as fishing and grazing, our ecological-economic system is

${ }^{5}$ For more on associated random variables and the approach that we shall follow in this paper, see Shaked and Shanthikumar (1994, pp. 114-120 and pp. 254-256) and Ross (1996, pp. 446-456). 
constantly being subjected to perturbations. Depending on the nature of the natural event and/or the economic activity, the ensuing perturbations will have different effects on the various species in our ecological-economic system. Consequently, at some arbitrary time $t$, a given species may or may not be functional, i.e., this species may or may not be able to provide a flow of services to society over time. To this end, let $s_{i}=1$ if the $i t h$ species is functional at time $t$, and let $s_{i}=0$ otherwise. Also, for $i \in[1, n]$, let $\operatorname{Prob}\left\{s_{i}=1\right\}=p_{i}$ denote the probability that the $i t h$ species is functional at time $t$.

As Perrings (1996) has noted, there will generally be some substitutability between species in the performance of ecological functions. Indeed, the work of Schindler (1990) and others tells us that the resilience of ecological functions in most terrestrial ecosystems is an increasing function of the number of substitute species that can perform those functions. To account for this substitutability, let us partition $S$, the ecological-economic system, into smaller subsets. We shall call these subsets compartments. Each compartment has the property that all the species that are contained in it are substitutes in the performance of ecological functions. ${ }^{6}$ Mathematically, we have compartments $C_{1}, \ldots, C_{q}$, where $1 \leq q \leq n$. The reader will note that $q=1$ corresponds to the case where the species in our ecological-economic system are perfect substitutes, and $q=n$ corresponds to the case where these species are perfect complements.

We are now in a position to describe the transient behavior of our ecological-economic system that is subject to perturbations. To this end, we shall say that at any time $t$, our ecologicaleconomic system's response to perturbations is given by the probability-Prob $\{e-e$ system functional $\}$ - that this system is functional. This probability is the

${ }^{6}$ This notion of a compartment is related to the notion of a guild in ecology. As Krebs (1985, p. 572) has noted, the species in a guild can be thought of as being functionally equivalent. 
transient resilience of our ecological-economic system. ${ }^{7}$ We now need a criterion for determining when our ecological-economic system is functional. A reasonable criterion would be to say that this system is functional if, and only if, at least one of the species in each of the compartments is functional. Note that this criterion is quite general and it effectively accounts for the substitutability issue that was discussed in the previous paragraph. Let us now determine the transient resilience of our ecological-economic system.

\subsection{Transient resilience}

At time $t$, let $S=1$ if the ecosystem is functional and let $S=0$ otherwise. Then it is clear that

$$
S=\prod_{i=1}^{q} w_{i}
$$

where

$$
w_{i}=\max _{j \in C_{i}} S_{j}
$$

Equation (3) tells us that the $w_{i}$ are increasing functions of the random variables that we have denoted by $s_{i}$. This observation, along with equation (1), and Proposition 9.7.1 in Ross (1996, pp. 446-7) tell us that the $w_{i}$ are associated. Consequently, we get

Transient Resilience $\equiv \operatorname{Prob}\{e-e$ system functional $\}=\operatorname{Prob}\{S=1\}=E[S]=E\left[\prod_{i=1}^{q} w_{i}\right]$.

Now applying the definition of association from equation (1) to the last expectation in equation (4), we get

$$
E\left[\prod_{i=1}^{q} w_{i}\right] \geq E\left[w_{1}\right] E\left[\prod_{i=2}^{q} w_{i}\right] \geq \ldots \geq \prod_{i=1}^{q} E\left[w_{i}\right] .
$$

From the previous discussion, we know that the $w_{i}$ are equal to either zero or one. In particular,

\footnotetext{
${ }^{7}$ Several recent papers in ecological economics have conceived of resilience as an appropriately defined probability. For more details, see Batabyal (1998b, 1999b) and Perrings (1998). Further, our interpretation of an ecological-economic system's transient behavior as an appositely defined probability is in the same spirit as the approached adopted in Perrings (1998).
} 
$w_{i}=1$ if, and only if, at least one species in each compartment $C_{i}$ is functional. Further, we also know that $\operatorname{Prob}\left\{s_{i}=1\right\}=p_{i}$. Putting these pieces of information together, we conclude that

$$
\text { Transient Resilience } \equiv \operatorname{Prob}\{e-e \text { system functional }\} \geq \prod_{i=1}^{q}\left\{1-\prod_{j \in C_{i}}\left(1-p_{j}\right)\right\} .
$$

Equation (6) provides us with a lower bound on the transient resilience of our ecological-economic system. To complete the analysis, let us now compute an upper bound for this system's transient resilience.

To compute this upper bound, it is helpful to rethink the species substitutability based compartmentalization of our ecological-economic system that was proposed in section 2.1. Recall that we had grouped species into compartments $C_{1}, \ldots, C_{q}$, so that our ecological-economic system is functional if, and only if, at least one species in each compartment is functional. Now consider an alternate grouping. In particular, we shall regroup the different species into compartments $D_{1}, \ldots, D_{r}$ so that our ecosystem is functional if, and only if, all the species of at least one of these compartments $D_{1}, \ldots, D_{r}$ are functional. The reader should note that given the original compartmentalization $C_{1}, \ldots, C_{q}$, it is always possible to find this alternate compartmentalization $D_{1}, \ldots, D_{r}$. Put differently, if we think of compartments as guilds, then this latter compartmentalization does not alter the species in our ecological-economic system; it is simply a different way of configuring the species in these guilds.

With this alternate compartmentalization, let

$$
x_{i}=\prod_{j \in D_{i}} S_{j}, i=1, \ldots, r .
$$

Note that because the $x_{i}$ are increasing functions of the associated $s_{i}$, by Proposition 9.7.1 in Ross (1996, pp. 446-7) it follows that the $x_{i}$ are themselves associated random variables. Using this fact, we get 
Transient Resilience $\equiv \operatorname{Prob}\{e-e$ system functional $\}=\operatorname{Prob}\{S=1\}=E\left[1-\prod_{i=1}^{r}\left(1-x_{i}\right)\right]$.

Now applying the properties of the expectation operator and using the definition of association from equation (1), the expectation in equation (8) can be simplified. This simplification gives

$$
E\left[1-\prod_{i=1}^{r}\left(1-x_{i}\right)\right] \leq 1-\prod_{i=1}^{r} E\left[1-x_{i}\right] \leq 1-\prod_{i=1}^{r}\left\{1-\prod_{j \in D_{i}} p_{j}\right\} .
$$

Putting equations (8) and (9) together, we get

$$
\text { Transient Resilience } \equiv \operatorname{Prob}\{e-e \text { system functional }\} \leq 1-\prod_{i=1}^{r}\left\{1-\prod_{j \in D_{i}} p_{j}\right\} .
$$

Finally, equations (6) and (10) together give us the central result of this paper. We state this result as

Theorem 1: The transient response of our ecological-economic system to perturbations is characterized by the notion of transient resilience. This notion is a probability, and this probability is bounded below and above as follows: $\prod_{i=1}^{q}\left\{1-\prod_{j \in C_{i}}\left(1-p_{j}\right)\right\} \leq \operatorname{Prob}\{e-e$ system functional $\} \leq$ $1-\prod_{i=1}^{r}\left\{1-\prod_{j \in D_{i}}\left(1-p_{j}\right)\right\}$.

Theorem 1 and the preceding discussion give us a formal method for quantifying the transient response of an ecological-economic system to perturbations from the occurrence of natural events and the continuance of economic activities. This quantification is in terms of a probability that we have called the transient resilience of the ecological-economic system. The reader should note that although exact expressions for the transient resilience of an ecosystem can be computed (see equations (4) and (8)), we believe that the bounds given in Theorem 1 are likely to be more useful to the manager of an ecological-economic system.

In order to compute these bounds, it will be necessary to perform two tasks. First, it will be necessary to obtain information about ecological functions, and particularly, the species which perform these functions. This information will enable an ecosystem manager to group substitute 
species into compartments, as described above. ${ }^{8}$ Second, an ecosystem manager will have to be knowledgeable about the probabilities indicating whether or not a particular species is functional, i.e., the $p_{j}^{\prime} s$. Possible means of acquiring this knowledge would appear to be indirect. Note that in order to be functional, a species must also be surviving. Consequently, it should be possible to proxy the $p_{j}^{\prime} s$ by means of survival probabilities. In turn, survival and death rates, and techniques used in the computation of ecological life tables should prove to be useful in obtaining estimates of these survival probabilities. ${ }^{9}$ Once these two tasks have been carried out, it will be possible to compute the transient resilience of an ecological-economic system. This measure can then be used to determine the effects of alternate management policies on the short term behavior of an ecologicaleconomic system.

\section{Conclusions}

In this paper we studied an important question in ecological economics that has not been addressed adequately in the economics literature previously. In particular, we showed how to quantify the transient response of an ecological-economic system to perturbations from the occurrence of natural events and the continuance of economic activities. This quantification involved the computation of bounds on a probability that we called the transient resilience of an ecologicaleconomic system.

The analysis of this paper can be extended in a number of different directions. In what follows, we suggest one possible extension. Our characterization of transient resilience depended

\footnotetext{
${ }^{8}$ Yodzis (1982) shows how an analysis of food webs can be used to compartmentalize real and assembled ecosystems. Also see Krebs (1985, pp. 570-572).

${ }^{9}$ For more on the relevant techniques, see Krebs (1985, pp. 164-165 and pp. 180-181) and the sources cited therein.
} 
on our use of the notion of statistical association. As indicated in section 2.1, this notion formalizes the idea of positive dependence between the species of an ecological-economic system. However, this formalization is undertaken in a rather specific manner. Consequently, additional research is needed to study (i) the nature of the interdependencies between the species of an ecologicaleconomic system, and (ii) the effects of these interdependencies on the transient resilience of the ecological-economic system.

Formal studies of ecological-economic systems which incorporate this aspect of the problem into the analysis will provide richer and more realistic characterizations of transient behavior. Such studies will also provide useful guidance about the management of ecological-economic systems whose short term behavior is often governed by a great deal of unpredictability. 


\section{References}

Batabyal, A. A. 1998a. The Concept of Resilience: Retrospect and Prospect, Environment and Development Economics 3, 235-239, 1998.

Batabyal, A. A. 1998b. On Some Aspects of Ecological Resilience and the Conservation of Species, Journal of Environmental Management 52, 373-378.

Batabyal, A. A. 1999a. Contemporary Research in Ecological Economics: Five Outstanding Issues. Unpublished Manuscript, Department of Economics, Utah State University.

Batabyal, A. A. 1999b. Species Substitutability, Resilience, and the Optimal Management of Ecological-Economic Systems, Mathematical and Computer Modelling 29, 35-43.

Cottingham, K. L., and Carpenter, S. R. 1994. Predictive Indices of Ecosystem Resilience in Models of North Temperate Lakes, Ecology 75, 2127-2138.

Dasgupta, P. 1996. The Economics of the Environment, Environment and Development Economics $1,387-428$.

DeAngelis, D. L. 1980. Energy Flow, Nutrient Cycling, and Ecosystem Resilience, Ecology 61, 764771.

DeAngelis, D. L. 1992. Dynamics of Nutrient Cycling and Food Webs. Chapman and Hall, London, England.

Hahn, F. 1982. Stability, in K. J. Arrow and M. D. Intriligator, (Eds.), Handbook of Mathematical Economics, Volume 2. North-Holland, Amsterdam, The Netherlands.

Holling, C. S. 1973. Resilience and Stability of Ecological Systems, Annual Review of Ecology and Systematics 4, 1-23.

Holling, C. S., Schindler, D. W., Walker, B. W., and Roughgarden, J. 1995. Biodiversity in the Functioning of Ecosystems: An Ecological Synthesis, in C. Perrings, K. Maler, C. Folke, C. S. Holling, and B. Jansson, (Eds.), Biodiversity Loss: Economic and Ecological Issues. Cambridge University Press, Cambridge, UK.

Ives, A. R. 1995. Measuring Resilience in Stochastic Systems, Ecological Monographs 65, 217-233.

Krebs, C. J. 1985. Ecology, $3^{\text {rd }}$ edition. Harper and Row Publishers, New York, USA.

Neubert, M. G., and Caswell, H. 1997. Alternatives to Resilience for Measuring the Responses of Ecological Systems to Perturbations, Ecology 78, 653-665. 
Perrings, C. 1996. Ecological Resilience in the Sustainability of Economic Development, in S. Faucheux, D. Pearce, and J. Proops, (Eds.), Models of Sustainable Development. Edward Elgar, Cheltenham, UK.

Perrings, C. 1998. Resilience in the Dynamics of Economy-Environment Systems, Environmental and Resource Economics 11, 503-520.

Pimm, S. L. 1984. The Complexity and Stability of Ecosystems, Nature 307, 321-326.

Pimm, S. L. 1991. The Balance of Nature? University of Chicago Press, Chicago, USA.

Ross, S. M. 1996. Stochastic Processes, $2^{\text {nd }}$ edition. Wiley, New York, USA.

Schindler, D. W. 1990. Natural and Anthropogenically Imposed Limitations to Biotic Richness in Freshwaters, in G. Woodwell, (Ed.), The Earth in Transition: Patterns and Processes of Biotic Impoverishment. Cambridge University Press, Cambridge, UK.

Shaked, M., and Shanthikumar, J. G. 1994. Stochastic Orders and Their Applications. Academic Press, San Diego, USA.

Yodzis, P. 1982. The Compartmentation of Real and Assembled Ecosystems, American Naturalist 120, 551-570. 